\title{
Iowa Coalition for Integrated Employment
}

\author{
Becky Harker $^{\mathrm{a}}$ and Amy Desenberg-Wines ${ }^{\mathrm{b}, *}$ \\ a Iowa Developmental Disabilities Council, IA, USA \\ ${ }^{\mathrm{b}}$ PIE Project Director
}

Revised/Accepted April 2017

\begin{abstract}
.
BACKGROUND: The Iowa Coalition for Integrated Employment (ICIE) is a large, cross discipline stakeholder group committed to expanding preparation, community placement and ongoing supports so that individuals with Intellectual and other Developmental Disabilities (I/DD) can realize personal community integrated employment outcomes. The ICIE led systems change efforts that involved collaborative activities such as, 1) pilot projects with provider sites to test the effectiveness of and the resource needed for implementation of customized employment, 2) pilot projects with school districts to incorporate four essential elements into their employment preparation of students with IEPs, 3) soliciting input to develop recommendations for changes in service definitions and reimbursement/funding for those services, 4) providing information, training, and engagement opportunities for families, 5) piloting outcomes data collection, and 6) offering capacity building opportunities for service provider and education staff.

OBJECTIVE: This article includes some of the background information that enhanced Iowa's readiness for Partnerships in Employment, the role of the ICIE in leadership and collaborative strategies that led to policy changes, increased provider engagement and employment outcomes for individuals with IDD.
\end{abstract}

CONCLUSION: Next steps are discussed.

Keywords: IOWA, customized employment, intellectual and developmental disabilities (IDD), community integrated employment

\section{Introduction}

Today's employment system in Iowa is the product of years of cross agency relationships, communication, project coordination and considerable stakeholder participation. Iowa's history of collaboration includes 13 years with a Memorandum of Agreement between seven State agencies whose representative administrators assumed responsibility for the development and deployment of resources and policies to strengthen employment outcomes for Iowans with disabilities. This group of administrators became known as the "Governance Group," and includes representation from the Iowa Departments of Education, Human Services, Workforce Development, the Blind, Human Rights, and Iowa Vocational

\footnotetext{
*Address for correspondence: Amy Desenberg-Wines, Iowa Coalition for Integration \& Employment, IA, USA. Tel.: +1 515 981 4113; E-mail: adesenbergwines@gmail.com.
}

Rehabilitation Services and the Iowa Developmental Disabilities Council. This collaboration positioned Iowa as an attractive recipient of a series of federally funded opportunities to test and implement promising and best practices including service navigators, benefits and work incentives counselors, post-secondary transition, data collection, parent engagement, and professional development.

The Governance Group was lobbied to act on growing stakeholder support for a statewide initiative to improve employment preparation, placement and ongoing support services for youth with disabilities where the preferred outcome is competitive integrated employment (CIE). The initial Employment First initiative, which was supported by Iowa APSE and the Medicaid Infrastructure Grant (MIG), the Department of Education's State Professional Development Grant (SPDG) and the State Employment Leadership Network (SELN), provided valuable 
information and feedback related to Iowa's current issues, challenges, strategies, and resources connected to CIE employment policy, practice, and funding. In addition, constituency groups which included representatives of state agencies, families, local providers, advocates, educators, service agencies and organizations met to review data, reach agreement on definitions of commonly used terms and set priorities to align all efforts towards CIE for youth with disabilities. The same six barriers kept emerging from all the projects and discussions. Probably the most telling barrier that was consistently identified was the absence of leadership driving Iowa's Employment First initiative. Iowa had been steeped in admiring the problem by repeatedly gathering to identify barriers and suggest goals, but lacked the leadership to move the discussion further into problem solving and implementation. The opportunity afforded by the Administration on Intellectual and Developmental Disabilities, through the Partnerships in Employment (PIE) grant, allowed Iowa to use the information gathered to develop and implement plans to achieve outcomes-based and systems-level improvements. Areas of focused work over the course of the PIE project included: 1) Affecting and facilitating sustainable systems change through a grassroots, statewide Coalition; 2) Developing a statewide data measurement system for employment outcomes; 3) Increasing preparation, placement and support services that begin early and lead to successful postsecondary transition; 4) Supporting service providers to align their mission, services and resources to promote CIE; 5) Increasing the expectation of and demand for CIE by all stakeholders, including family members; and, 6) Influencing and aligning policies, practices and funding to support CIE.

\section{Background}

Despite the activities described above, the state of the state related to employment preparation, placement and ongoing support was less than stellar. At the time the proposal was submitted for the Partnerships in Employment (PIE) project, competitive, integrated employment was not an outcome that most Iowa youth with disabilities experienced. Follow-up data from the Iowa Department of Education for 2009/2010 showed that $80 \%$ of students who had Individualized Education Plans (IEPs) in high school were employed one year after high school. However, only $20 \%$ of those were employed in integrated settings, earned at least minimum wage, worked for at least 35 hours a week and held their jobs for 90 days. The data suggested that $60 \%$ of high school graduates with IEPs were under-employed and another $20 \%$ were not engaged in either employment or postsecondary education. Through the SPDG activities, IEPs had been improved statewide such that $69 \%$ contained the six essential elements of a good transition plan. This was better than the $20 \%$ reported at the beginning of the grant, but still below the national threshold of $75 \%$. Parents of students with IEPs surveyed reported expectations for their son or daughter to work and live on their own but also, reported that they did not have the necessary skills to do so (e.g. budgeting, work behaviors \& skills, laundry, etc.). Through the SPDG, training modules on transition planning, raising expectations, employment preparation and exploring post-secondary options were developed for parents and delivered by Parent and Educator Partnership representatives within each of Iowa's regional Area Education Agencies.

In Iowa's 2011 state fiscal year (ending June 30 , 2011) there were approximately 8,000 adults accessing the Medicaid Home and Community Based Services (HCBS) Intellectual Disability Waiver. The number of individuals who were actively accessing supported employment services was 1,404 (18\%). The remaining 6,596 (82\%) individuals were not engaged in supported employment activities. The funding ratio of public dollars (state and federal) spent on Employment Services further illustrates the state of employment services for Iowans with developmental disabilities, as $80 \%$ of ID waiver dollars were spent on facility-based services and only $20 \%$ on community-based services.

"Payer of last resort" was a term often used by those trying to understand and use the vocational rehabilitation and Medicaid service systems to pay for individualized employment services. The perceived absence of consistent guidance for providers caused them to struggle with billing for services in a complex system, and resulted in providers second guessing who paid for which services for the individuals seeking supports.

\section{Key project activities}

\subsection{Coalition building}

The ICIE project began with a "Core Team" comprised of representatives from the four required 
agencies (Iowa Developmental Disabilities Council (DD Council), Iowa Vocational Rehabilitation Services (IVRS), Department of Education (IDE), and Department of Human Services (DHS)) that signed onto the Memorandum of Agreement required by the proposal. These four agencies had been previously engaged in the Governance Group. In addition to these four, representatives from former and existing projects were invited to join the Core Team representing Medicaid, the Employer Disability Resource Network (EDRN), community rehabilitation providers (CRPs), and the Olmstead Consumer Task Force. The functions of the Core Team were to: 1) Ensure grant function, 2) Clarify policy/practice (short term implementation), 3) Facilitate long-term systems change \& improvement, and 4) Grow a coalition of stakeholders to shape the work.

The Core Team strategically identified a list of people who were sent an invitation to attend the first meeting of the Coalition. Consideration was given to the diversity of geography and experience. The Core Team also sought balance between state agency staff, family members, individuals with disabilities and community service providers as well as between administrators and direct service staff. Preparing the list came easily because of the previous number of individuals attending employment-related stakeholder and input meetings. Those who attended the first Coalition meeting were asked if there were others who should be attending and were asked to reach out to them.

The Coalition grew from 49 members (2012) to 243 diverse stakeholders (2016). Stakeholders included Iowans with disabilities, family members, community rehabilitation providers, case managers, State Agency representatives, Managed Care Organizations, and educators. Growth of the Coalition was largely due to an inclusive and engaging culture. People learned of the Coalition from those already attending, as well as through presentations about the Coalition and through their attendance at other meetings or conferences where the Coalition's work was discussed. Those interested were welcomed, included and put to work. Some expressed concerns that 243 people were too many to really function as a coalition. However, there was enough work that people could direct their energies to the pieces that were of the most interest or best used their skills and experience. As a result, work groups were established as needed, and targeted conference calls and smaller focused meetings, separate from the Coalition Meetings, were held to address specific deliverables associated with the ICIE project. The full Coalition met quarterly to review implementation, monitor and evaluate activities, learn about specific topics and make connections between segments of the work, and to grow a sustainable advocacy force dedicated to long-term systems change. During Coalition Meetings, members also heard from specific stakeholder panels such as individuals with IDD, educators, and family members about their interests, needs and roles in CIE.

During the first meeting of the Coalition, facilitators were asked, "Are you trying to close sheltered workshops?.” An important strategy for engaging stakeholders in the Coalition was to honor the history and work of those who provide case management and employment, and to refrain from any mention of closing facilities. Instead, conversations focused on how to build on previous work to transform and extend the continuum of services to include more integrated, community-based supported employment service options. Coalition meetings provided an opportunity to share information about research and best practices in employment, as well as to understand the implications of emerging Federal legislation, regulations and guidance on practice and expectations in Iowa.

Engaging people in productive and lasting systems change requires that stakeholders see that they are welcome at the table and that their concerns, barriers, observations, experiences and talents are recognized. People who were advocating for the closure of "sheltered workshops" caused those working in or using the facilities (staff, clients, and families) to dig in their heels and strongly advocate against closure. However, very few found fault with expanding available employment services options to increase opportunities for skill building, trying out different environments and tasks, and pursuing interests. That's the message the Core Team consistently asked the coalition members to use. The Core Team intentionally worked to ensure that the Coalition meetings were respectful of all opinions and experience. Discussion of different views led to understanding, relationship building and, ultimately, reaching consensus on solutions to address barriers.

However careful the Core Team was with their language, there were members of the Coalition who were not as careful and probably but inadvertently offended some of the providers. The Core Team response was to ask the providers to give a history 
of the concept of the facility-based services. Two representative providers described the historical context in which they had been working to provide employment services. They made two points that seemed to resonate with the audience: 1) they are doing the best they can with the information they've received and, 2) they are providing the services the system reimburses them to provide.

The Core Team communicated clear expectations and modeled trust and respect for individuals and opinions. It worked to build purposeful relationships between diverse stakeholders and foster collaboration. Coalition members acknowledged the team's culture and also reported: 1) there is a shared vision for change; 2) opinions and ideas are valued; and 3 ) engagement is worthwhile, meaningful and contributes to improving Iowa's system.

The Coalition was routinely asked for formal and informal feedback that helped shape the work and the focus of Coalition meetings. A survey of members during the 4th year of the project found that participants experienced positive changes in knowledge (80\%), attitudes (78\%), skills (61\%), actions (74\%), beliefs $(61 \%)$ and whether their opinions were valued $(100 \%)$. The fact that $100 \%$ of the respondents said they felt their opinions were valued was celebrated by the Core Team as having accomplished an important milestone in developing an effective and collaborative coalition.

\subsection{Leadership and oversight of coalition efforts}

A key element to Iowa's successful engagement of a large Coalition for far reaching statewide systems change was the use of independent contract staff who served as the backbone of the project. Without the prior allegiance to any one entity, the contract staff came to the project without preconceived notions of the role and strengths of the various entities engaged. They asked questions that otherwise might not have been asked by staff with previous experience and relationships. Staff further supported the project by providing strategic coherence between pieces of the work. Responsibilities of contract staff that contributed included:

- Serving as a neutral convener facilitating effective dialogues and engagement;

- Managing evaluation, data collection, and use of results;

- Building key relationships across the state with different but related initiatives;
- Developing effective communication and advocacy agendas; and

- Staying connected and maintaining a presence related to CIE.

Another key element was the fluid leadership assumed by Coalition Members who took action including volunteering to pilot solutions, serving on work groups, mentoring others, taking initiative and engaging in conversations to seek out solutions to barriers, speaking to legislators, engaging in conversations at the community level and challenging one another on employment outcomes for individuals served. This shared leadership also extended to the State Agencies involved, as agency representatives stepped up to facilitate groups tasked to complete work related to the agencies' realm of responsibility. Examples include leaders from the Department of Education on the Model Education Transition Sites pilot project; IVRS on funding and services questions; Department of Human Services on reviewing the Administrative Rules. In addition, the Iowa Developmental Disabilities Council took the lead with policy and public awareness activities for National Disability Employment Awareness Month activities such as creating and disseminating videos of individuals talking about their work and issuing press releases and proclamations.

Iowa was also awarded an Employment First State Mentoring Leadership Project (EFSMLP) from the U.S. Department of Labor's Office of Disability Employment Policy (ODEP) which had similar goals and objectives related to increasing employment services, provider capacity and employment services redesign. IVRS was the lead agency for that project. EFSLMP and ICIE leadership engaged in early planning to determine how to eliminate duplication and use resources collaboratively to meet mutual objectives of the two projects. Shared leadership emerged as a key strategy as members of the EFSMLP project team were on the Coalition, and Coalition Core Team members served on the EFSMLP team. The ICIE project originally planned to implement three pilot projects with CRPs. However, through a joint effort, the number of pilots increased to six. The availability of Subject Matter Experts (SMEs) through EFSMLP expanded the opportunities for training and technical assistance offered to the CRPs engaged in the pilots and, eventually, to a larger group of providers interested in transforming their services and programs to be more community-based. 


\subsection{Informing employment services redesign}

The strength of Iowa's approach to redesigning employment services was the strong cross-agency and stakeholder collaboration. The collective leadership of the EFSMLP, ICIE, and SELN efforts and the commitment of each project's leadership to work together to leverage knowledge, resources, and strategies without duplicating efforts made each project stronger and led to greater overall outcomes for the state.

In 2013, the Department of Human Services entered into a stakeholder engagement process with prevocational and supported employment stakeholders to redesign the HCBS Prevocational and Supported Employment services. This Employment Services Redesign was intended to bring HCBS prevocational and employment services into compliance with the definitions and service structure provided by the Centers for Medicare and Medicaid Services (CMS) in their 2011 bulletin and the 2015 1915(c) Technical Guide. The ICIE contribution to this effort began with its commitment to share resources with EFSMLP to increase the number of community rehabilitation provider pilot sites from three to six. The purpose of the pilots was to increase the capacity of providers to prepare, place and support individuals with intellectual and developmental disabilities (IDD) in integrated, community-based employment settings. The strategy used was to introduce customized employment as a best practice, begin to explore how to implement the components of the practice, and ask providers to collect implementation data. Each of the pilot sites was asked to identify people with IDD who had previously been deemed "unemployable" to be the targets for customized employment services. Site staff then participated in a three-day workshop and received coaching from an EFLMP subject matter expert (SME). Pilot sites also had individualized monthly conference calls and site visits with the SME for on-going training and technical assistance.

The availability of the SME benefitted provider staff. The SME modeled components of Customized Employment through hands-on field experience with job seekers. The SME could observe the job seeker and subsequently had a frame of reference when provider staff called to problem solve when they got stuck along the way. Providers experienced success quickly, with 14 of the original 30 targeted job seekers gaining employment within the first year.

The pilots were able to use a combination of funding (e.g., HCBS Waiver, IVRS and county dollars) to support some of the components of customized employment. These projects helped identify gaps in funding services and provided information to IVRS and Medicaid to inform necessary rate restructuring. Pilot sites reported that funding for the discovery services in customized employment was not available through the "traditional" IVRS reimbursement structure. That was resolved when IVRS added a new Discovery service code to their menu of services. Pilot site reports of time and cost data demonstrated where staff was investing time in service delivery, thus informing IVRS and Medicaid of the need to better align service options with funding. Findings from pilot projects fed into work by the SELN to assess Iowa's Medicaid funding structure and consider alternative structures to support integrated employment services. Guidance documents prepared by SELN provided several key assumptions for Iowa to consider when rebalancing the rates. Leveraging ICIE resources, those key assumptions were shared in public community forums across the state to increase awareness of the intent to rebalance Iowa's employment service system to support integrated community employment and to gather feedback on the assumptions. During these community forums, participants were invited to apply to participate on the Employment Services Redesign workgroup. This workgroup included representatives of CRPs from large and small communities across the state, case managers, family members, IVRS, Medicaid, and Iowa's Division of Mental Health \& Disability Services (MHDS) and the Department of Education. EFSMLP resources allowed for the SME to facilitate the Redesign Workgroup and, eventually, to draft recommendations. Between workgroup meetings, those ICIE members most interested in funding and policy met to review drafts and provide feedback. Multiple documents and resources were also made available to the public including individuals with disabilities and family members. Recommendations for employment service definitions, provider requirements, staff qualifications, staff training, reimbursement methodologies and a funding transition model were submitted to the Iowa Department of Human Services (DHS) in December of 2013.

As time elapsed with no response or follow-up from DHS, many of those who were engaged and supportive of the recommendations became frustrated and wrote to DHS staff asking for updates. DHS was most responsive to those inquiries by family members and, as a result, began to work with SMEs from the EFSMLP to draft Administrative Rules based on 
the recommendations submitted. Once Administrative Rules were drafted, the process appeared to stall again. It wasn't until family members spoke with their legislators, who then asked questions of DHS, that the process began moving forward again. The Medicaid HCBS Employment Service Administrative Rules were finally adopted in May 2016.

The new Administrative Rules: 1) revise service definitions to match the Centers for Medicaid and Medicare Services (CMS) Bulletin (2011) and 1915(c) Waiver Technical Guide (2015), 2) change reimbursement rules including the fee schedule and the definition of billable activities to allow reimbursement for supports provided "on behalf of" and not in the presence of an individual, 3) redistribute some Medicaid resources to strengthen employment rates, 4) influence an increase in the array and quality of individual employment supports/services available, 5) align DHS and IVRS policy and funding, and 6) establish a monthly rate structure for Long Term Job Coaching Tiers that encourage "fading" over time, in favor of natural supports.

\subsection{Developing an outcome measurement system}

The Governance Group had consistently discussed the barriers to creating a statewide employment outcome data collection system. Barriers included variances in data collected, different definitions of employment across agencies, disparate populations for whom outcome data was reported, as well as incompatibility of data systems. The Iowa Medicaid Infrastructure Grant (MIG) intended to support the development of an outcome measurement system related to CIE for individuals with disabilities. The ICIE Core Team coordinated with staff who had worked on the MIG, and with SELN, to review existing core employment outcome measures and identify sources of outcome data for Iowans receiving Medicaid funded long term supports and services. The ICIE Core Team, MIG staff and SELN consultants had multiple conversations and facilitated a full day meeting with diverse stakeholders who provided recommendations and feedback to determine meaningful outcome measures. Because of that meeting, three core outcome variables were recommended to be the basis for employment data measurement in Iowa: work status, hours worked and wages. The ICIE Core Team reviewed and adopted these three performance measures to describe individual outcomes as a measure of system performance to be used in the course of the PIE. Ultimately, the Outcome and Performance Measures Workgroup of the MHDS Redesign adopted these measures as well to assess MHDS funded services statewide.

ICIE then sought and received MHDS approval for staff support to pilot and test a data collection method for gathering individual level information on outcomes of employment related services provided with public funds. A secondary goal was to obtain some baseline data which would be useful to gauge the impact of the employment systems change work in process. In addition, the pilot would collect process information from providers so that feedback could be used to develop a convenient data collection and reporting system to gather meaningful data moving forward.

Nineteen CRPs from 29 locations, and representing 12 of the 14 MHDS Regions across Iowa, participated in the data collection pilot. Providers, representing small and large organizations, were recruited through individual contacts, meetings with ICIE staff, and through consultation with MHDS Regional CEOs. They represented all parts of the state, including both urban and rural locations. An unduplicated total of 2,104 persons received services during a two-week period. The number of hours worked, the wages earned and the services setting (individual, group or facility) was collected and reported on an individual basis. Those receiving job development services were also reported. Many people received more than one service during the reporting period.

Providers reported they did not view the data collection process and tool to be burdensome. Additionally, they reported the information was useful and expressed willingness to collect the data on an ongoing basis. Two MHDS Regions adopted the data collection tool and process for their ongoing required monthly reporting by CRPs.

\subsection{Pilot demonstrations: Model Employment Transition Sites (METS)}

The Model Employment Transition Sites (METS) were pilot projects designed to determine services, supports and procedures that lead to effective ongoing preparation, placement and support services for students beginning early in high school and resulting in employment outcomes. The Department of Education and IVRS staff collaborated on the METS to determine selection criteria for pilot sites and provide training, technical assistance, oversight and 
reporting. The project began with a review of the literature completed by TransCen (2012) for the Iowa Department of Education to determine essential elements around which to build the framework for effective employment preparation programs. The elements included:

1. Early planning and experience to focus student career preferences

2. Early and ongoing collaboration

3. Paid work experience

4. Support and follow-up to maintain employment.

The staff reviewed data to determine those school districts that, based on the data, appeared to be more effectively transitioning students to employment and/or post-secondary education. Data points were pulled from IVRS and Department of Education systems level data, including Indicator 14 data and IVRS Student Status Reports, as well as individual IEPs and IVRS Case Reviews. The higher performing school districts were asked whether they were interested in participating in the pilot project. Five volunteered and participated in team reviews of the data with the Department of Education and IVRS staff. As staff and local district teams reviewed and discussed initial data they came to the realization that their current approach was not yielding the desired employment outcomes for students. This led to discussions about what each of the districts needed/wanted to do to improve outcomes, and each developed annual plans to pursue them. Districts were not required to address all four of the essential elements in their annual plans. Instead each determined which area(s) on which to focus.

\subsubsection{METS strategies}

The METS reported that the four essential elements were helpful in guiding and shaping their assessment, planning and implementation. They viewed the essential elements as both the interventions and outcomes. They conducted ongoing gap and trend analyses, incorporating targeted action planning to address gaps and to secure opportunities for students that aligned with the four elements.

Each of the five sites engaged in curriculum development to deficits and gaps. This helped to align the curriculum to the newly adopted Iowa Core, district initiatives, community agency services and community opportunities. Curriculum development included skills identified by community partners and district staff as important prerequisites to successful employment and/or post-secondary education. Curriculum development was deemed beneficial to the sites that fully completed the process.

Many sites used the Positive Personal Profile (PPP; Tilson, n.d.) as a strategy to change the way school district staff and partners assess and create visions with the students. It provided a communication tool for team members and partners, and provided a positive lens through which others, including families, viewed the student. Participants reported that the PPP led to partners talking more positively about students and their future employment. It led to a more holistic view of individual students and helped increase expectations for employment outcomes after high school. One participating METS using the PPP saw the value and expanded its use to include all secondary students in the district.

Determining the flow of services created defined and clear roles and responsibilities of school staff and partners. It connected the curriculum with services and supports. It also improved relationships and collaboration between partners, including increased parent engagement at intake and planning and providing support to families. The flow of services also assisted to connect students with needed community supports and services.

All five sites offered work experiences to students. Student work outcomes and an increase in access to a variety of work experiences were achieved at all sites. Integrated work experiences helped shift and cement METS partners' thinking towards an expectation of employment for students. Site staff experienced an increase in capacity to provide job site supports and services to students along with increased access to a variety of work experiences being offered at all sites. Summer work programs were implemented. The use of Discovery as a strategy led to changes in approaches to employers. One district sought and received administrative approval to shift two paraprofessional positions to job coaches because of successes experienced.

\subsubsection{Next steps for METS}

The original plan for the METS was that ICIE would have a validated system of preparation, placement and ongoing supports to transition students to posts-secondary employment and/or education by the end of the project. Some faulty assumptions as well as some unknowns discovered during implementation, hindered the ability to scale up the practices to statewide implementation. Several of the assumptions and unknowns were explored during site visits with each 
Table 1

Common roadblocks to successful transition efforts

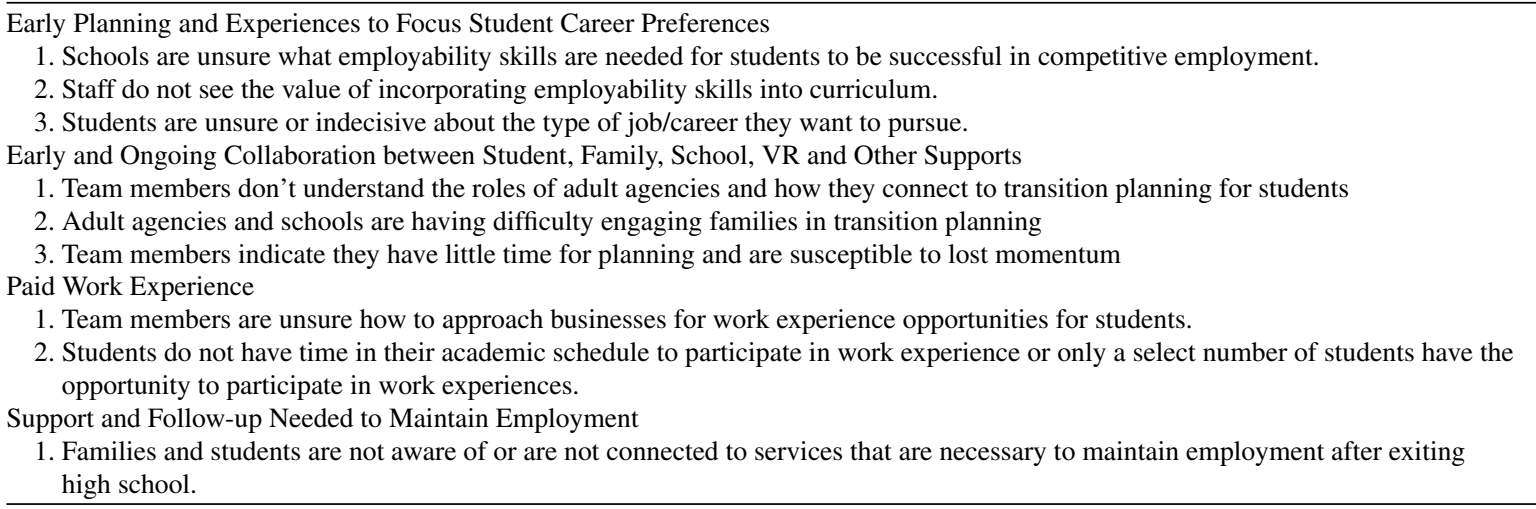

of the METS, discussed during Core Team and Coalition Meetings, and included in a unpublished report titled Iowa Model Employment Transition Sites Operational Guide (2015), which was submitted to the Department of Education by TransCen, Inc. (Table 1).

The final year of the project focused on lessons learned for the five METS. Each site had determined its scope of work, but all sites did not complete the same work or follow the same project time frame. Some developed strategies to address the roadblocks described previously, but these were not consistent across sites. However, each site brought information to the table that was presented and synthesized to develop an overarching understanding of lessons learned, continuing support needs and next steps.

Areas of commonality among the sites included the importance of communication, curriculum mapping, professional development and data analysis. Sites had varying levels of success with building staff competencies and community capacity. Protocol types and templates for effective communication needed to be developed to help sites develop a plan to communicate project intent and implementation to both internal and external stakeholders. Curriculum mapping was beneficial to those sites that completed the process. However, a common approach needs to be developed to support an analysis of curricula and subsequent mapping.

The original five districts were engaged with METS leadership to determine staff development needs, implementation structures, a coaching model, structure and tools to be used with future sites. These provide the basis for regional consultants at the Area Education Agencies (AEAs) and Local Education Areas (LEAs) to assess student needs relative to work preparation, reviewing curriculum and processes, developing teams to assist with student work experiences and integrating these processes into their system. The Department of Education and IVRS are now engaged in planning to continue the work in the five original sites and to implement the lessons learned. A workgroup of members across the state that includes stakeholders from LEAs, AEAs, IVRS and Department of Education are meeting to plan for scaling up the work.

\section{Major accomplishments}

The ICIE created an important platform to bring together multiple parallel initiatives focused on common outcomes, and used inclusive coalition building strategies to coalesce around unified goals for employment systems change. Bringing pieces of the work to the whole coalition, a diverse group of stakeholders, led to cross boundary education and awareness of one another's parameters, constrictions, solutions and achievements. It helped members of the Coalition to see the bigger picture of preparation, placement and supports for CIE and offered entrées into local and statewide discussions and suggestions for local collaboration.

ICIE became a focal point through which leadership was developed, encouraged, fluid, situational and continual. People stepped up and took a leadership role in those areas in which they felt competent and passionate. Partnering with other federally funded projects allowed for broader coverage, more resources to a greater audience and engagement on a statewide level.

The Coalition used multiple efforts to build capacity of CRPs to align their mission and services to support CIE outcomes for clients. Seventy-nine different CRPs were involved in activities such 
as: intensive pilot projects, monthly community of practice $(\mathrm{CoP})$ webinars, a mid-management leadership development series, topical workgroups, a data collection pilot, technical assistance to transform services and regional and statewide training events. CRPs that regularly participated in the Coalition significantly shifted their delivery of services resulting in an increase in the number of Iowans with significant service needs, who had previously been deemed unemployable, obtaining CIE. Seeing these individuals achieve CIE seemed to be an important trigger for providers who not only began to see opportunities but expressed increased confidence in their ability to provide services that produced CIE outcomes for individuals. Data collected from the CRP pilot projects is depicted in Table 2 below.

The pilot projects with the CRPs resulted in observations and feedback that influenced policy. IVRS observed the outcomes for people who had previously been deemed unemployable and decided the agency would no longer term people "ineligible" for services. Both IVRS and Iowa Medicaid Enterprise staff realized a need to make responsibility for funding services clearer so that providers could be confident they were submitting appropriate billing statements to the right entity. IVRS and Iowa Medicaid Enterprise entered into an MOA delineating responsibility for funding services to braid funding streams. IVRS also created an additional service code for reimbursement for Discovery services. When CRPs later reported the reimbursement rate did not adequately cover the service, IVRS raised the rate.

The concept of CIE was new to Iowa's school district staff who had become accustomed to referring students to local facility-based programs. As a result, there was a strong need to develop staff capacity and increase expectations. School districts with strong administrative leadership progressed further than those without.

The structure of the METS pilot in five Iowa school districts provided strategies each would implement but allowed the districts flexibility to determine
Table 3

METS pilot participant data

\begin{tabular}{lccc}
\hline Year & 2012 & 2013 & 2014 \\
\hline $\begin{array}{l}\text { Applicants (students with } \\
\text { an open file with IVRS) }\end{array}$ & 94 & 206 & 148 \\
Average hourly wage & $\$ 10.83$ & $\$ 10.54$ & $\$ 12.55$ \\
Average hours worked & 37 & 33 & 37 \\
\hline
\end{tabular}

what they proposed to do. Rather than adopting a systems change approach, the districts tended to approach employment preparation and placement on a student by student basis. Table 3 below includes employment outcome data for students in the METS. Through this individual student approach, the METS identified critical activities and data elements consistent with the Workforce Innovation and Opportunities Act (WIOA) that includes: job exploration, work readiness training, work-based learning experiences, counseling and opportunities, and selfadvocacy instruction. Based on critical elements identified through the METS, and data elements that will measure impact, the IDE and IVRS have begun to develop a Model Project for school districts and a five-year plan for collaborative work. The model will be used to prepare students for CIE through work opportunities and experiences.

Changes to Iowa's Medicaid Administrative Rules aligned funding, service definitions, and provider qualification requirements to support CIE services. The adoption of these rules occurred one month after the State's transition from a Medicaid fee-for-service model to a Managed Care model. The timing was unfortunate in that providers were already dealing with a lot of changes in their operations, and individuals served and their families were confused and anxious about the purpose of the rules, the purpose of Managed Care and what it would mean in terms of their day to day lives. Managed Care Organizations (MCOs) participated in Coalition conversations and training opportunities, and regularly attended coalition meetings which has resulted in the three MCOs promoting CIE and using information and tools developed.

Table 2

Outcomes of CRP pilot projects

\begin{tabular}{lccccc}
\hline Year & $\begin{array}{c}\text { \# of Jobs } \\
\text { Obtained }\end{array}$ & $\begin{array}{c}\text { Wage/ } \\
\text { Hour }\end{array}$ & $\begin{array}{c}\text { Hours } \\
\text { Worked/Week }\end{array}$ & $\begin{array}{c}\text { \# of Customized } \\
\text { Jobs }\end{array}$ & $\begin{array}{c}\text { \# Providers } \\
\text { Reporting Data }\end{array}$ \\
\hline 2013 & 14 & $\$ 7.70$ & 14 & 0 & 6 \\
2014 & 427 & $\$ 7.81$ & 17.27 & 86 & 12 \\
2015 & 725 & $\$ 8.31$ & 15.93 & 150 & 18 \\
TOTALS & 1,166 & $\$ 7.94$ avg. & 15.73 avg. & 236 & \\
\hline
\end{tabular}


Outcome data collection methods piloted with 19 providers helped establish a baseline of information and demonstrated that the collection process was not burdensome on providers. Agency Administrators consistently commented that they couldn't ask CRPs to do more by asking them to collect individual outcome data. While it's true that CRPs were not interested in additional paperwork, they did see the value of having a means to determine whether changes they were implementing made a difference for individuals. Engaging the CRPs in the discussion, asking them to participate and provide feedback, and narrowing the time period for data collection to a single point in time all seemed to be strategies that worked well to gain buy-in and assistance. The feedback CRPs provided on the process was valuable and resulted in most of those participating asking to adopt the tool and process. Efforts to gather this data continue, and outcome reports will soon be submitted by the MCOs who pay for supported employment services.

\section{Next steps}

Successful achievement of individual CIE outcomes seemed to have the greatest impact on raising expectations across stakeholders. Individuals, families, job coaches, educators, administrators and legislators responded positively when given the data from pilots and presented with stories from individuals who were working for the first time in the community. The question becomes how the ICIE can keep the momentum going to focus on increasing hours worked to the level people need and want and ensuring that individuals are engaged in meaningful activities in the community during non-work time.

The Coalition continued to grow over the course of the 5 years of the project, and at the end of the project period, people wanted the Coalition to continue. As a result, efforts are underway to register the Coalition into a nonprofit 501(c)3 organization with the State of Iowa. The Core Team decided to change the name to the Iowa Coalition for Integration and Employment to be able to broaden the scope of its activities to embrace and impact other aspects of community inclusion for Iowans with IDD.

During conversations about sustainability the Coalition members indicated a strong need for continued training and technical assistance supports for provider staff to continue to develop the skills and confidence to prepare, place and support individuals in CIE. Conversations about how to accomplish that resulted in the Iowa Association of Community Providers soliciting a proposal from ICIE to provide those services. The proposal submitted was funded so those services will continue. In addition, IVRS provided funding for continuation of the $\mathrm{CoP}$ webinars on topics related to furthering opportunities for CIE in Iowa.

\section{Conflict of interest}

None to report.

\section{References}

Centers for Medicare \& Medicaid Services. (2015). Application for $\S 1915(c)$ Home and Community-Based Waiver: Instructions, technical guide and review criteria. Retrieved from http:// www.nasddds.org/uploads/documents/Version3.5Instructions Jan2015.pdf

Centers for Medicare \& Medicaid Services. (2011). CMCS informational bulletin: Updates to the $\S 1915($ c) waiver instructions and technical guide regarding employment and employment related services. Retrieved from https://downloads.cms.gov/ cmsgov/archived-downloads/CMCSBulletins/downloads/CIB 9-16-11.pdf

Crane, K., Hyatt, J., \& Allison, R., (2015). Iowa Model Employment Transition Sites operational guide. Unpublished Report.

Tilson, G. (n.d.). Developing a positive personal profile. Retrieved from https://www.dol.gov/odep/ietoolkit/publications/501.pdf

TransCen, Inc. (2014) Effective Employment Preparation, Placement, and Support Strategies: A Review of Literature. Unpublished Report. 